Est Ag 51 (2016) 5-36

\title{
Pedro en la historia de Jesús según Marcos
}

\author{
Luis Ángel Montes Peral
}

RESUMEN: Dos cuestiones cruciales trata de responder el Evangelio de Marcos: ¿quién es Jesús? y ¿qué significa ser discípulo suyo? Estas dos preguntas convergen, de modo paradigmático, en la persona, vocación y misión, o dicho de otro modo, en la historia de Pedro, el personaje más importante del escrito marquino después de Jesús. En el intencionado relato cristológico del evangelista comprobamos, y así lo exponemos de modo pormenorizado, cómo Pedro responde vitalmente a este reto, con sus luces y sus sombras, convirtiéndose en el modelo de referencia del ser discípulo de Jesús. Seguir el comportamiento de Pedro y asimilar todo aquello que es positivo en él, en las páginas vivas de esta singular obra, ayuda como nada a ser cristiano aquí y ahora.

ABSTRACTO: The Gospel of St. Mark attempts to answer two crucial questions: Who is Jesus? What does it mean to be one of his disciples? These two questions converge, in a paradigmatic way, in the person, vocation and mission - or in other words - in the story of Peter, the most important person in Mark's writings after Jesus himself. This article aims to reveal in detail that the Gospel writer's intentionally Christological account shows Peter's life to be a response to the challenge of being a disciple, with all its highs and lows. That response made Peter the model for disciples of Jesus and thus the pages of this unique living work are of the greatest help to Christians here and now who wish to imitate his example and take on board all that is positive in him.

La figura de Pedro adquiere una especial relevancia en el Evangelio de Marcos (EvMc)ํ. Simón (1,16.29.30.36; 3,16; 14,37), a quien Jesús le

\footnotetext{
${ }^{1}$ No sólo el Ev. de Mc, lo mismo podemos afirmar del resto de los evangelios. Su preeminencia en ellos no deja lugar a dudas. La mayor información sobre Pedro proviene de la obra lucana $(\mathrm{Lc}+\mathrm{Hch})$, aunque en sus respectivos evangelios Mc lo nombra una vez más
} 
confirió el nombre de Pedro $(3,16)$ y con cuya denominación se le identifica a lo largo y ancho de las páginas del escrito marquino (5,37; $8,29.32 .33 ; 9,2.5 ; 10,28 ; 11,21 ; 13,3 ; 14,29.33 .37 .54 .66 .67 .70 .72 ; 16,7)$, es con mucho el discípulo mejor abordado por el evangelista, recibiendo su figura un tratamiento muy especial, que podemos calificar de exclusivo ${ }^{2}$. Ningún otro personaje - exceptuamos por supuesto a Jesús - es tan nombrado como él, destacando por encima de todas las demás personas y convirtiéndose además en el creyente más representativo de la historia del cristianismo. No resulta exagerado afirmar que nos jugamos parte de nuestra propia identidad religiosa en la detallada consideración de Pedro como personalidad de carne y hueso, captada en sus trazos esenciales por nuestro evangelista 3 .

que Lc. Las primeras referencias a Pedro proceden de Gal 1,19;2,6-14; 1 Cor 1,12;3,22; 9,5; 15,5. En Gálatas la actuación petrina no deja de ser ambivalente. Fuera de estos textos es mencionado en las cartas pseudoepigráficas 1 Pe 1,1 y 2 Pe 1,1. Pero el EvMc, el más antiguo de los evangelios, constituye la fuente más segura para acercarnos a la biografía de Pedro. Los datos que nos suministra Pablo, anterior a Marcos, son muy escasos.

2 En la exégesis marquina actual los especialistas destacan con fuerza el protagonismo de Pedro: «Pedro llena todo el evangelio de Marcos. Se le encuentra en todas las páginas y cada vez más en un primer plano» (G. MinetTe de Tillese, Le secret messianique dans l'Evangile de Marc [Paris 1968] 439). «Simón Pedro es una persona muy relevante dentro del grupo de los Doce y de los discípulos, la más relevante después de Jesús» (A. Rodríguez Carmona, «La figura de Pedro en el Evangelio de Marcos» en R. Aguirre Monasterio, Pedro en la Iglesia primitiva [Estella, Navarra 1991; Verbo Divino] 33).

3 Con todo, «la importancia histórica y teológica del pescador de Betsaida ha sido minusvalorada en los círculos tanto evangélicos como católicos» M. Hengel, Saint Peter: The understimated Apostle (Gran Rapids 2010) IX. «Tras siglos de ser el hijo olvidado de la exégesis crítica de la Biblia (sobre todo la protestante), en las últimas décadas el interés por su figura ha conocido un notable reconocimiento. Cada vez más estudiosos - protestantes y católicos - trabajan para ofrecer una imagen menos polarizada y más constructiva de la función que desempeñaba Pedro en la primera generación del movimiento de Jesús» (M. Bockmuelhu, Simón Pedro, en la Escritura y en la memoria [BEB 142; Salamanca 2014; Sígueme] 9). En el campo protestante destaca la obra pionera de O. Culmann, Petrus, Jünger-Apostel-Märtyrer (Zürich/ Stuttgart 1952; Zwingli Verlag). En el católico el libro escrito en colaboración entre católicos y protestantes de los Estados Unidos, R. E. BRown, K.P. Donfried y J. Reumann, Peter in the New Testament (Minneapolis - New York 1973; Augsburg Publishing House). Existe traducción castellana, Pedro en el Nuevo Testamento (Santander 1976; Sal Terrae). Corroborando los datos anteriores, podemos afirmar que en los últimos cien años se ha estudiado hasta la saciedad el Evangelio de Marcos y en él a Jesús, el Cristo Hijo de Dios, su protagonista absoluto. Pero en cambio se ha postergado bastante la figura de Pedro, su personaje secundario más importante. Mi aportación va a ser bien sencilla, pero quiere ser significativa: Abordando a fondo el puesto de Pedro en Marcos, pretendo estudiar la importancia crucial de Pedro, sobre todo en su Historia de la 
Dos cuestiones básicas se plantean en la obra de Marcos: ¿Quién es Jesús? y ¿qué significa ser cristiano como seguidor de Jesús? Pedro constituye la figura clave, que da respuesta verbal y existencial a estas preguntas cruciales planteadas; respuestas que se irán desentrañando en este estudio. La Historia de la Pasión, la parte más importante del EvMc, nos informa cómo la fe de Pedro naufraga de modo estrepitoso; fe que será restablecida por obra y gracia del Resucitado. Pedro aparece como la figura más paradigmática entre los seguidores del Maestro.

Desde el primer momento conviene aclarar, que en el escrito marquino Pedro se alza como un ser real con señas de identificación intransferibles. El mayor acierto de su vida estuvo en haber seguido al Maestro de Nazaret y contribuido significativamente a que su causa se extendiera por el mundo. Su persona ofrece perfiles tan convincentes del ser cristiano, que reflejan al creyente de todas las épocas del cristianismo con su posición y comportamiento. Marcos presenta su figura en su verdad histórica, vinculada a Jesús y a su seguimiento. Y así debe ser entendido y valorado por el fiel lector del Evangelio, so pena de falsearlo.

Siguiendo estas pautas, atendemos en este estudio a tres perspectivas complementarias: A) La histórica, que se deduce de los datos fehacientes de la biografía de Pedro. B) La cristológica, que une a Pedro con Jesús mediante vínculos indestructibles de sincero compromiso. C) La testimonial, que surge sobre todo en los acontecimientos centrales de su vida, que pueden servir de modelo a los creyentes de hoy en su tarea de seguir a Cristo. Pedro no puede reducirse a la arqueología histórica, conserva vida palpitante, que conviene auscultar e imitar.

\section{A) LA PERSPECTIVA HISTÓRICA ${ }^{4}$}

Empezando con la primera característica, fundamento de las demás, no nos queda más remedio que atenernos a los datos fehacientes de su vida, ya que el evangelista nos proporciona «los contornos fundamentales

Pasión, un documento excepcional, que se remonta en el tiempo treinta años antes que la redacción de la obra marquina.

4 M. DE BuRgos, «Simón Pedro, ideología e historicidad en las tradiciones neotestamentarias», en R. Aguirre Monasterio, Pedro en la Iglesia primitiva, o. c. 235-258. Para una síntesis breve y certera de la biografía de Pedro, cf. C. P. März, Petrus. Sein Leben, sein Wirken und seine Zeit (Leipzig 2011; Benno). En este librito encontramos los datos, acontecimientos, lugares y hechos, que nos ayudan a conocer en la forma debida a esta figura clave de la historia de Jesús y de la primitiva comunidad. 
del retrato de Pedro que es normal entre la mayoría de los cristianos» ${ }^{5}$; contornos por cierto que en su contenido básico corresponden a la verdad histórica6. Queremos así referirnos primero a los nombres que porta, que nos proporcionan la medida de su actuación ${ }^{7}$; más tarde precisaremos los lugares propios de su actuación, en los que quedó consignada su impronta, para luego pasar a presentar lo específico de su misión y de su comportamiento en relación con el acontecimiento de la fe. Aquí voy a referirme, por lo tanto, a tres concreciones significativas, que tienen que ver con su persona y las circunstancias propias de su acontecer.

\section{Los nombres de un personaje excepcional}

Marcos confiere dos nombres al primero de los discípulos: el de Simón y el de Pedro ${ }^{8}$. Nunca aparecen ambos unidos en una sola denominación, Simón Pedro, como en el resto de los evangelios, especialmente en $\mathrm{Jn}^{9}$. En la constitución del grupo de los Doce informa, que Jesús cambió de nombre a Simón: «Simón, a quien puso el nombre de Pedro». Con todo Jesús se dirige a él con el nombre de Simón $(14,37)$.

\subsection{Simón}

El nombre propio es el bíblico de Simón. Su padre se llamada Juan o Jonás, de modo que nuestro protagonista llevaba como sobrenombre Barjona $(B \alpha \rho \iota \omega v \alpha)$ y así lo proclama Jesús en una ocasión solemne entre las solemnes (Mt 16,17ss) ${ }^{10}$. Desconocemos el nombre de su madre. Tampoco

5 R. E. Brown, K.P. Donfried y J. Reumann, Pedro en el Nuevo Testamento, 62. Marcos no se muestra propetrino ni antipetrino (cf. A. Rodríguez CARMONA, «La figura de Pedro en el Evangelio de Marcos» 34-39), sencillamente es realista y fiel a su línea teológica. Toma datos fehacientes sobre Pedro, provenientes de la tradición, los introduce en su escrito y les hace revivir para el anuncio del Evangelio.

6 Un buen resumen de esos contenidos pueden verse en R. E. BROwn, K.P. DONFRIED y J. Reumann, Pedro en el Nuevo Testamento, 62-67.

7 El nombre para los semitas tiene una importancia fundamental; dice mucho más que para las personas de nuestra cultura actual (cf. L. Á. Montes Peral, El Padrenuestro. La oración trinitaria de Jesús y los cristianos [Estella, Navarra 2001; Verbo Divino] 86ss).

8 Marcos menciona 26 veces a nuestro protagonista: 19 como Pedro y 7 como Simón. No se trata de una casualidad que Pedro sea la primera persona, que aparece en la actividad pública de Jesús $(1,16)$.

${ }^{9}$ Mt 4,18; 16,16; Lc 5,8; Jn 13,6.36; 18,10.15.25; 20,2.6; 21,2.11.15.

10 La segunda parte del sustantivo compuesto muestra una abreviatura del nombre hebreo Johanan, Juan en griego. Hijo de Juan, por lo tanto. La denominación no aparece en Marcos. 
sabemos si los padres vivían, cuando conoció a Jesús y si, además de Andrés, tenía otros hermanos y hermanas. Su familia biológica, como la del mismo Jesús, alcanza muy escasa relevancia en las páginas de nuestra obra (6,1-6), interesada más bien en la familia de los hijos y hermanos del reino (3,31-35).

El nombre de Simón o Simeón aparece muy poco en el Primer Testamento: Es el segundo hijo de Jacob, padre de una de las tribus (Ap 17,7), también un hijo de Judá, según Lc 3,30. Del mismo modo encontramos este nombre en alguna lista de israelitas, que regresaron de la cautividad de Babilonia (1 Cron 4,20). En la época helenista adquirió una importancia fundamental, en el juego político de la segunda mitad del siglo II a. C., otro Simón, el último y más presuntuoso de los hijos de Matatías, el que podemos considerar como el fundador de la dinastía de los asmoneos (142-134 a. C.). Cuando desaparecieron sus hermanos, los llamados macabeos, se convirtió en rey y sumo sacerdote de los judíos, adquiriendo un poder político y religioso desconocido hasta entonces (1 Mac 13-16) ${ }^{11}$.

Los evangelios ofrecen sin excepción el nombre griego de Simón para referirse a Pedro ${ }^{12}$. Lo hacen no porque ambos tuvieran ascendencia griega, sino porque vivían en una ciudad muy influida por la cultura helenista. De ahí que no tenga que sorprendernos que su hermano llevara un

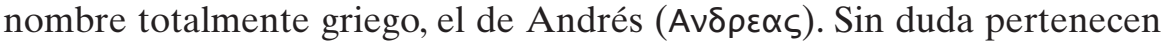
a una familia judía por los cuatro costados, como deja muy claro Pablo, que llegó a conocerlo muy bien, en Gal 1,14 con ocasión de la disputa que tiene con él en el famoso incidente de Antioquía. Dada su actividad pescadora, quizá tuvo que vérselas con no pocos paganos. Éstos pudieron helenizar su nombre. El hebreo Simeón sólo lo encontramos en dos textos bien significativos: Hch 15,14 y 2 Pe 1,13.

11 En esta época aparecen varios Simones, un famoso sumo sacerdote (Eclo 50,1-23) y otro de la tribu de Benjamín (2 Mac 3,4.11;4,1-6), cuyo hermano fue también sumo sacerdote de triste memoria: Menelao (2 Mac 4,23).

12 El nombre de Simón es también griego. Lo encontramos ya en Aristófanes. Pudo muy bien ocurrir que el nombre hebreo de Simeón se sustituyera por el griego de Simón, que sonaba de forma muy semejante y que encajaba mejor en una ciudad de cultura helenista, como era en la población, en la que había nacido. Que Betsaida había nombres griegos lo prueba el hecho de que Andrés y Felipe, naturales también de esta población, sean nombres griegos. Tampoco podemos descartar que el nombre de Simón fuera puesto por los cristianos de habla griega, ya que les resultaba más fácil la pronunciación. Lo que sí es cierto es que la versión griega de su nombre, independientemente de su origen, fue la que más se extendió a partir de la segunda mitad del siglo I d. C.

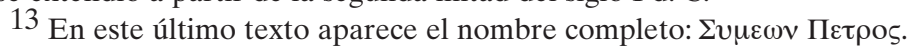


En el Segundo Testamento contamos con un buen número de personajes, que llevan este nombre, sobre todo en el EvMc. En la historia primera de Jesús, en su estancia en Galilea, aparecen dos personas más con ese nombre: Simón el de Caná14, uno de los Doce $(3,18)$, y Simón de Nazaret, uno de los primos - hermanos de Jesús, junto con Santiago, José y Judas $(6,3)$. En la historia de la pasión encontramos otros dos con el mismo nombre: Simón, el leproso (14,3), en cuya casa de Betania tiene lugar la unción de Jesús por parte de una mujer, cuyo nombre no se menciona (14,3-9); y Simón, natural de Cirene, el padre de Rufo y Alejandro $(15,21)$, que a la fuerza ayudó a Jesús a llevar la cruz y cuya familia era bien conocida por la comunidad primitiva ${ }^{15}$.

\subsection{Pedro}

Siguiendo una tradición judía en personas de especial significación, Jesús cambió su nombre y le puso el de Pedro, según asegura el evangelista en la elección y constitución del grupo de los Doce $(3,13)^{16}$. Sobre todo es esta dominación, con la que más se le identifica a lo largo de las páginas no sólo del escrito de Marcos, también del resto de los evange$\operatorname{lios}^{17}$. Y así el nombre de Pedro aparece 23 veces en Mt, 19 veces en Mc, 18 veces en Lc, 56 en Hch y 34 en Jn. En el EvMc el nombre está la mitad de las veces, nueve en concreto, en la historia de la pasión, el texto que nos

\footnotetext{
14 Lc 6,15, le llama «zelote» ( blemente ocultó Marcos en el intento de despolitizar su obra. Transformó el griego, por el patronímico resultante de una población: Caná de Galilea $(3,18)$.

15 Por el EvJn sabemos que el padre de Judas Iscariote llevaba este nombre (6,72; 13,2.26). En la obra lucana aparece el anciano Simeón ( Lc 2,25.28.34) y un tal «Simeón, llamado Níger» (Hch 13,1), uno de los profetas cristianos de Antioquía de Siria; también Simón, «el mago» (Hch 8,9.13.18.24) y «Simón curtidor» (Hch 9,43; 10,6.17.32), en cuya casa se hospedó Pedro durante su estancia en Jafa.

16 En realidad no sabemos ni siquiera con mediana certeza, cuándo sucedió el cambio de nombre. Cierto es que Jesús cambió el nombre a Pedro. Pero el momento exacto ofrece tres tradiciones concurrentes: Según Mc 3,6 sucedió con ocasión de la constitución del grupo de los doce. Según Mt 16,17 inmediatamente después de la confesión de Cesarea de Filipos. Según Jn 1,42, cuando tiene lugar el primer encuentro de Jesús con Pedro. Los tres coinciden que sucedió durante la actividad en Galilea. Una polémica, que no se ha cerrado sobre todo en la exégesis protestante, consiste en establecer, si fue el Jesús terreno, quien cambió a Pedro de nombre o más bien fue obra de la primitiva comunidad (cf. E. DinkLER, «Petrus, Apostel»: $\left.R G G^{3} 5,247\right)$. Pienso que no hay razones de peso para negar credibilidad en este punto a los evangelistas.

17 En el Segundo Testamento aparece 154 veces (cf. J. LuJÁn, Concordancias del Nuevo Testamento [Barcelona 1975; Herder] 430s).
} 
proponemos analizar de un modo especial. A veces se unen ambos nombres y tenemos así el completo: Simón Pedro, que en lo referente a Mc aparece sólo en dos ocasiones: 3,16;14,37.

Marcos no menciona el término de Kefas, que con seguridad fue el nombre arameo que Jesús impuso a Pedro, como sostiene el cuarto evangelio (Jn 1,42). El evangelista, que nos ha transmitido una palabra aramea excepcional de Jesús: $A b b a(14,36)$, así como dos de sus expresiones en esa misma lengua: Talitha qumi y Eloí Eloí, lema sabactaní $(5,41 ; 15,34)$, en esta ocasión se limita a proporcionarnos la traducción griega del nombre: Pedro, que significa piedra, roca.

Con todo conviene resaltar, que la primera tradición cristiana, testi-

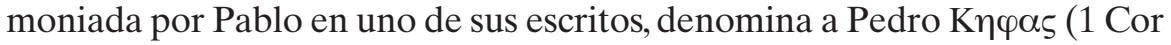
$1,12 ; 9,5)$; lo que nos lleva a aventurar que las mismas comunidades helenistas primitivas conocían al príncipe de los apóstoles con el nombre arameo impuesto por Jesús y que sólo más adelante se tradujo al griego. Quizá para simplificar las cosas y no dar pie a posibles malentendidos, Marcos menciona ya a nuestro protagonista exclusivamente con denominación griega, no haciéndose problema alguno con el tema de los nombres ${ }^{18}$.

\section{Los principales lugares de su actuación}

Betsaida, Cafarnaún, Cesarea de Filipos y Jerusalén constituyen lugares significativos y hasta etapas centrales en la vida itinerante del Pedro en comunión $-\mathrm{y}$ en los últimos momentos en distanciamiento - con la historia de Jesús de Nazaret. Las otras poblaciones de la geografía de Palestina, por las que pasa Pedro, no tienen la importancia de las señaladas; de ahí que prescindamos de ellas.

\subsection{Betsaida ${ }^{19}$}

Desconocemos el año de nacimiento de Simón Pedro. Con los datos que tenemos sólo podemos hacer conjeturas. Según Jn 20,1-10 era mayor

\footnotetext{
18 Este substantivo arameo es traducido en la Septuaginta por $\lambda \iota \theta 0 \varsigma$, es decir: piedra, nombre cargado de simbolismo, sobre todo en el Evangelio de Mateo.

${ }^{19}$ Marcos menciona Betsaida en dos ocasiones: como lugar de retiro de Jesús con sus discípulos $(6,45)$ y como población, en la que Jesús cura a un ciego $(8,22-26)$. Nada nos dice acerca de la estrecha vinculación de Pedro con esta población, hasta el punto de haber nacido en ella. La tradición marquina da a entender, más bien, que Pedro «era originario de Cafarnaún» (cf. M. DE BuRGos, «Simón-Pedro, ideología e historicidad en las tradiciones neotestamentarias», en R. Aguirre Monasterio, Pedro en la Iglesia primitiva, 239). Hay que sostener además, que coloca su vocación y misión en esta población.
} 
que el discípulo que Jesús quería, ya que corría menos que él, por lo que podía tener en aquel momento una edad provecta. Según Jn 21,18 murió cuando era viejo. Para el entendimiento de entonces se entraba en la vejez ya con cincuenta años. Ninguna información nos refiere Marcos que nos aproxime a su edad. Posiblemente pudo nacer unos años antes del comienzo de la era cristiana. Era algo mayor que Jesús, al menos así nos lo ha transmitido siempre la iconografía.

Su lugar de nacimiento es Betsaida, cuyo nombre hebreo significa casa de la pesca ${ }^{20}$. Situada en la Galaunítide inferior en la orilla oriental del Jordán, estaba muy cercana a su desembocadura del río en el mar de Galilea (1,16), como llama Marcos al lago Kinneret (Num 34,11; Jos 13, 27). Aunque la población era judía, la influencia de las poblaciones limítrofes helenistas era grande. Sus habitantes estaban habituados al trato con los gentiles e incluso llevaban nombres griegos, como ya hemos constatado en el caso de la familia de Pedro. Desde su infancia tuvo contacto continuo con el Lago de Genesaret, un espacio natural considerable con una longitud de 21 y una anchura de 12 kilómetros. Las aguas pueden tener una profundidad de 42 y hasta de 48 metros. Podemos conjeturar que pronto aprendió a pescar en él.

Posiblemente su niñez y juventud la pasó en esta población. Sin duda la estrecha vinculación al lago de Galilea prende ya en sus primeros años. Allí pudo permanecer hasta el momento de su casamiento. Con bastante seguridad se trasladó entonces a Cafarnaún, siguiendo el oficio de pescador, aunque ahora por cuenta propia y con contactos profesionales con su hermano Andrés, probablemente su socio en el negocio de la pesca, y con la familia de Zebedeo.

\subsection{Cafarnaún}

Hemos comentado ya, que Pedro nació en Betsaida, aunque no es un dato transmitido por Marcos. Pero su oficio de pescador lo ejerció, no sabemos cuánto tiempo, sobre todo en Cafarnaún, una renombrada aldea, que distaba pocos kilómetros de Betsaida, a la que se podía acceder a pie bordeando el lago. Junto con su hermano Andrés, tenía su casa allí, según la valiosa información que nos proporciona el mismo Marcos

\footnotetext{
20 Se trata de una noticia, que nos ha transmitido ocasionalmente el cuarto evangelio: «Felipe era de Betsaida, ciudad de Andrés y de Pedro» (Jn 1,45). Algunos ponen en duda este dato joánico (cf. M. DE BuRGOS, «Simón-Pedro, ideología e historicidad en las tradiciones neotestamentarias», en R. Aguirre Monasterio, Pedro en la Iglesia primitiva, 239s).
} 
$(1,29)^{21}$. Posiblemente la suegra de Pedro vivía con ellos o en una casa contigua. Esto nos lleva a la conclusión de que estaba casado, quizá con una cafarnauita. Desde luego esa casa sirvió de lugar apropiado para el anuncio de la buena noticia del reino y la realización de milagros $(1,32$; $3,20)$. La curación de la suegra fue toda una deferencia por parte de Jesús, para quien le había permitido usar sus bienes.

No conocemos el nombre de la mujer de Pedro; tampoco si tenía hijos. Casi seguro que no los tuvo, ya que no se los menciona nunca ${ }^{22}$. Si los hubiera tenido, hubieran dejado algún rastro en la tradición neotestamentaria, como fue el caso de la familia de Simón de Cirene $(15,21)$, un personaje bien poco relevante, de quien conocemos el nombre de dos de sus hijos, por ser conocidos y pertenecer a la comunidad cristiana. No tomamos en consideración las noticias de los apócrifos, sacadas de una tradición poco fiable 23 . También se menciona, aunque de manera indirecta, a su mujer ${ }^{24}$.

En Cafarnaún empieza una nueva vida para Pedro al amparo de Jesús. Le acompaña con asiduidad y de él aprende su nuevo estilo de vida. Tuvo que entusiasmarse mucho, porque desde entonces deja a su familia, su trabajo y, llegado el momento, también la población en que se ganaba su sustento, siguiendo al Maestro de Nazaret por los caminos de Palestina $^{25}$. Aquí, no obstante, pasan algunas cosas dignas de ser remarcadas.

\footnotetext{
21 Lc 4,38 afirma taxativamente que después de salir de la sinagoga de Cafarnaún, Jesús «entró en la casa de Simón», no mienta a Andrés como propietario.

22 Marcos y el resto de los evangelistas tampoco mencionan que tuvieran descendientes los otros componentes del grupo de los Doce. Pero en este caso no podemos afirmar ni negar nada, ya que la gran mayoría de los Doce no son objeto de particular reflexión por parte de nuestro evangelista. Desconocemos tanto datos personales como familiares sobre ellos.

23 Hechos de Pedro menciona una «hija doncella» de Pedro, «una bella mujer», creyente y enferma, ya que «uno de sus costados se halla totalmente paralizado, y se encuentra tendida en un rincón» (cf. Hechos apócrifos de los Apóstoles I. Hechos de Andrés, Juan y Pedro [BAC 646; Madrid 2004] 540). La credibilidad de este dato es nulo y no lo tomamos en cuenta.

24 Pablo hace también referencia a la esposa de Pedro, que le acompañaba en sus viajes apostólicos (1 Cor 9,5). Puede ser que no todos los misioneros estuvieran casados. Sorprende que en este pasaje Kefas sea mencionado en último lugar, aunque sea de forma individual. No cabe duda que en la comunidad de Corinto Pedro ocupó un papel preeminente, como puede deducirse de 1 Cor 1,12.

25 Sobre el llamamiento de Jesús a Pedro y los otros primeros discípulos, cf. L. Á. Montes Peral, Tras las huellas de Jesús. Seguimiento y discipulado en Jesús y los Evangelios (Madrid 2006; BAC) 17-20.
} 
Empieza a conocer más de cerca a Jesús, lo mismo que sus enseñanzas y sus acciones portentosas.

Puede ser que en Cafarnaún empezaran los diálogos polémicos con los grandes del pueblo. No cabe duda que Pedro, conociendo su carácter, se metería de lleno en ellos, como se deduce del altercado referente a la recolección de espigas por parte de los discípulos en un sábado $(2,23)$, tiempo en el que la ley prohibía realizar trabajos como recolectar espigas. Sin duda Pedro se pondría al lado de su Maestro, aunque el texto no recoja aquí ninguna actuación suya al respecto.

\subsection{Cesarea de Filipos}

En las cercanías de esta ciudad tiene lugar un acontecimiento, cuyos actores principales son Jesús y Pedro, que marcará más tarde como pocos la historia del cristianismo. Recordamos la escena, que ocupa el puesto central del Evangelio, tal como la describe Marcos: «Jesús y sus discípulos se dirigieron a las aldeas de Cesarea de Filipo; por el camino preguntó a sus discípulos: “¿Quién dice la gente que soy yo?”. Ellos le contestaron: "Unos, Juan el Bautista; otros, Elías, y otros, uno de los profetas". Él les preguntó: "Y vosotros, ¿quién decís que soy yo?". Tomando la palabra Pedro le dijo: "Tú eres el Mesías". Y les conminó que no hablaran a nadie acerca de esto" (8,27-30). Más adelante nos referiremos a la especial trascendencia de esta confesión ${ }^{26}$.

\subsection{Jerusalén}

No deja de sorprendernos el protagonismo de Pedro en la historia de la pasión. Después de Jesús sobresale sin duda su comportamiento, que deja por cierto más sombras que luces. De forma explícita surge su nombre y actuación en algunos de los episodios más sobresalientes del relato: en el diálogo mantenido durante la cena pascual (14,27-31); en la impresionante escena de la oración de Getsemaní (14,33-42); durante el juicio judío mantenido contra Jesús (14,54. 66-72); en el anuncio de la resurrección y de una aparición en Galilea, con que concluye el relato (16,1-8)27. No aparece en el juicio de Jesús ante Pilato, en la muerte de Jesús en la

\footnotetext{
26 La escena de Marcos tiene que ser completada con las palabras de Jesús a la confesión de Pedro en Mt 16,17-19, que no van a ser objeto de reflexión aquí, pero de excepcional importancia en el destino petrino.

27 Los otros evangelios completan el protagonismo de Pedro, sobre todo Lucas y Juan. Mientras en Marcos son dos discípulos no identificados los encargados de los preparativos para la cena pascual $(14,13)$, en Lc 22,8 s son precisamente Pedro y Juan los envia-
} 
cruz, ni tampoco en su sepultura. El capítulo 15 guarda silencio sobre él, dadas sus negaciones.

\subsection{Galilea y Jerusalén en concurrencia}

Para Simón Pedro Galilea, su región de procedencia, constituye la tierra bendita de la fidelidad y hasta del triunfo. Jerusalén, la ciudad maldita de la traición y del fracaso. Lo que ocurrió durante la actividad pública del Maestro Jesús, ocurre en buena medida también en la de su discípulo predilecto.

A pesar de su falta de entendimiento en no pocas de las enseñanzas del Maestro, en Galilea Pedro camina al lado de Jesús, siguiendo sus pasos, descubriendo los secretos íntimos de su corazón: va conociendo lo que encierra el secreto del reino. Sobre todo por los caminos del norte de Palestina, junto con los otros integrantes del grupo de los doce y hay que pensar que formando pareja con su hermanos Andrés $(6,7)^{28}$, Pedro anuncia con entusiasmo la conversión, expulsa a los demonios, unge con aceite a los enfermos y practica curaciones $(6,12)$. En no pocas ocasiones está incluido en la actividad de los acompañantes de Jesús; en las luces y sombras que se dan en el grupo en su continuo peregrinaje, haciendo el bien en pequeñas poblaciones $(1,22.27 ; 2,12.18 \mathrm{~s} ; 4,10 \mathrm{~s} .34 .41 ; 5,20$; $6,30.45 .50-52 ; 7,17.37 ; 8,1.15-21)$. El está en el meollo mismo de la actuación de Jesús y seguro que sobresalió por la ilusión que ponía en cuanto decía y hacía.

Para Pedro, más tarde también para nuestro evangelista, Jerusalén representa una ciudad en claroscuro. Recibe entusiasta a Jesús $(11,1-10)$ y días después le lleva a la cruz $(15,21-39)$. Algo que Pedro sin duda sintió en lo más íntimo y socavó su misión. Fue en el atrio del palacio del sumo sacerdote donde Pedro tuvo la mayor crisis de su vida creyente, como más adelante veremos con detenimiento.

\footnotetext{
dos por Jesús para preparar y comer la cena pascual. Encontramos también unas palabras, de las más importantes referidas a Pedro, que no aparecen en los otros evangelistas: «Simón, Simón, mira que Satanás os ha reclamado para cribaros como trigo. Pero yo he pedido por ti, para que tu fe no se apague. Y tú, cuando te hayas convertido, confirma a tus hermanos» (Lc 22,31s). En el cuarto evangelio es Pedro, no «uno de los presentes», como sostiene Mc 14,47, quien corta la oreja a Malco, el criado del sumo sacerdote (Jn 18,10). Pero sobre todo en Jn 20 y 21 destaca con fuerza el protagonismo de Pedro en el descubrimiento de la tumba vacía y en las apariciones del Resucitado.

28 Según 6,7 Jesús envió a los doce «de dos en dos». Hemos de suponer que Pedro formara pareja con su hermano Andrés, con el que aparece unido al comienzo de la misión $(1,16.29)$.
} 


\section{B) LA PERSPeCtiva CRISTOLógica}

Es la más importante de las tres. De alguna manera las otras dos confluyen en el conocimiento y en el seguimiento de Jesús, el Maestro y Mesías, el Hijo de Dios y el Salvador. El hombre se juega la vida en la praxis del discipulado: «porque quien quiera salvar su vida, la perderá; pero el que pierda su vida por mí y por el Evangelio, la salvará» $(8,35)$.

\section{1. ¿Quién es Pedro en la historia de Jesús?}

En la descripción marquina la personalidad de Simón Pedro ofrece una gran riqueza de rasgos y está cargada de sutiles matices. Entre el resto de los personajes sobresale como el primero de los discípulos, como el más impulso y activo; también como el más comprometido con la causa del Evangelio. Perteneciente al grupo de los Doce, aparece como el primer mencionado en su lista. Con relativa frecuencia actúa como su portavoz, representando repetidamente al conjunto del discipulado ${ }^{29}$. Bajemos

29 En la historia del primer cristianismo también aparece como garante de las tradiciones evangélicas. No encontramos esta función petrina de modo explícito en el EvMc, pero podemos deducirla de testimonios fehacientes de la tradición y del estudio interno de la obra marquina. En este caso concreto procede del Padre de la Iglesia Papías, obispo de Hierápolis, de la primera mitad del siglo II. Es bien conocido el testimonio que nos proporciona sobre el autor del segundo evangelio y que ha recogido Eusebio de Cesarea en su famosa Historia Eclesiástica: «Y el Presbítero decía esto: Marcos, intérprete que fue de Pedro, puso cuidadosamente por escrito, aunque no con orden, cuanto recordaba de lo que el Señor había dicho y hecho [...] de suerte que Marcos en nada se equivocó al escribir algunas cosas tal como las recordaba» (HE III 39,15). Si esto es así, el garante del escrito de Marcos es Pedro. Sus relatos dependen de su predicación y de un modo muy especial la historia de la pasión. De ahí que narre las negaciones de un modo tan realista, sin evitar ofrecer la crudeza de la traición cometida. Pero no sólo las negaciones, también otros episodios de su vida, en los que aparecen sus sombras, como la falta de entendimiento de las enseñanzas del Maestro, la seria reprimenda que tuvo que darle por no entender el sentido doliente de su mesianismo, sus inoportunidades etc. No olvidemos que Marcos es el que más critica la actuación de los discípulos, de un modo muy especial la de Pedro. Vamos a prescindir de esta función petrina, por no estar recogida directa e inmediatamente en el EvMc y no todos admiten la veracidad del testimonio de Papías. «Hoy día son muchos los que, aun admitiendo la posibilidad de que Pedro subyazca a algún material de Marcos (por ejemplo en la curación de la suegra de Simón, 1,30-31), no se sienten demasiado inclinados a aceptar la tradición de Papías» (R. E. Brown, K.P. Donfried y J. Reumann, Pedro en el Nuevo Testamento, 21). Pero conviene no desecharlo de todo. Llegado el momento, se puede recurrir a él, sin forzar el sentido y el contenido de la Palabra de Dios, transmitida en el Evangelio. No podemos descartar que la historia de la pasión de Marcos tenga como fuen- 
ahora al detalle, que es donde mejor brilla la valía de su atrayente persona. Con trazos breves describimos su fuerte personalidad así:

\subsection{Discípulo de la primera hora}

Según Marcos, al que siguen los otros sinópticos, le cabe a Pedro el honor el haber sido el primer discípulo de Jesús. Elegido por él como el primero de todos, sin duda con toda la intención, en modo alguno como fruto del azar. Efectivamente fue el primero en dos sentidos complementarios: a) cronológicamente es al primero que invita a su seguimiento, asegurándole a él y a su hermano Andrés que les haría "pescadores de hombres»; b) primero también en los esfuerzos por su formación: es al que más tiempo dedicó, con el que más habló y a quien encomendó misiones más relevantes ${ }^{30}$.

Acompaña por los caminos de Galilea al Maestro en momentos bien significativos, que tienen que ver sobre todo con hechos prodigiosos realizados por su Señor $(1,29 ; 3,13-16 ; 5,37 ; 9,2)$. Predice sus negaciones $(14,30)$, se dirige a él en la hora decisiva en que va a comenzar su pasión $(14,37)$ y le anuncia que le verá en su tierra, cuando resucite $(14,28-31$; 16,7). Por su parte Pedro despliega unas cualidades en el acompañamiento de Jesús, que no pueden ser silenciadas. Es el primero que le confiesa como Mesías $(8,29)$; el primero que goza de su presencia transfigurada $(9,5)$; el primero que le pregunta por la paga a recibir por haberle seguido (10,28-30). Además, siempre como primero en la lista, pertenece al trío más cercano a Jesús, juntamente con los hermanos Zebedeos (5,37; 9,2; $14,33)$ o a los cuatro primeros, junto a los anteriores y a su hermano Andrés $(1,29 ; 13,3)$.

\subsection{Apóstol del reino}

Tanto el discipulado como el apostolado, que son inseparables en la intención de Jesús ${ }^{31}$, están siempre íntimamente unidos con la buena noti-

te principal, o como alguna de sus más valiosas fuentes, la más primitiva predicación de Pedro. Desde luego estará siempre unido a este Evangelio como uno de los testigos fehacientes de sus relatos; un testigo privilegiado que fue espectador y actor de lo relatado y que supone el puente de unión entre la historia de Jesús y las enseñanzas de las primitivas comunidades.

30 Esto que ya aparece en el EvMc, queda corroborado hasta la saciedad en el resto de los evangelios. En Mc se insinúa más que se afirma explícitamente.

31 En la intencionalidad de Jesus sus seguidores son llamados en la medida que son enviados. Como llamados son discípulos, como enviados son apóstoles. Porque precisamente eso es lo que significa «apóstol»: «enviado» $(6,30)$. 
cia de la llegada del reino. Inmediatamente después de darnos el resumen de la predicación de Jesús, en el que entra de lleno el reino (1,15), Marcos habla del llamamiento de Pedro y de los otros discípulos $(1,16.19)$. Cuando aborda la misión de los Doce, no menciona directamente el encargo de anunciar el reino, pero se supone por el contexto, ya que salieron «a predicar la conversión» $\mathrm{y}$ «echaban demonios» $(6,12 \mathrm{~s})$, que ambas realidades constituyen partes inherentes al anuncio y a la venida del reino $(1,14 \mathrm{~s})$. El reino se va haciendo realidad operante, cuando la persona acepta el cambio de vida y las fuerzas antidivinas en sus diversas formas retroceden con la colaboración humana.

Los Doce, encabezados por Pedro $(3,16)$, reciben una enseñanza especial sobre el mensaje central de la predicación de Jesús: « $A$ vosotros se os ha dado el misterio del reino de Dios; en cambio a los de fuera todo se les presenta en parábolas» $(4,11)$. Aunque son duros de entender y débiles en la expresión de la fe, Jesús les proporciona catequesis complementarias «a solas» sobre temas centrales de su predicación $(6,31 ; 9,28 ; 10,10.42)$. No les falta buena voluntad para seguir las directrices de Jesús y ponerse al servicio del reino.

\subsection{Portavoz en momentos especiales $(1,36 ; 8,29 ; 9,5 ; 10,28 s ; 11,21)$}

En casi todos los episodios, en que están presentes los íntimos del Maestro de Nazaret, Pedro se encuentra implicado con un protagonismo bien resaltado. Con relativa frecuencia representa ante su Maestro al grupo de los Doce o al más amplio de los discípulos, destacándose así que tiene un puesto especial a lo largo de todo el Evangelio. Conviene resaltar la expresión: «Simón y sus compañeros» $(1,36)$. Con ella se quiere destacar de forma clara a Simón como representante de los discípulos, el que habla en su nombre 32 .

La primera vez que se muestra esta faceta tiene que ver con la curación de los enfermos, que se agolpan en torno a Jesús. Después de retirarse muy de madrugada, antes de amanecer a un descampado para orar, Simón y sus compañeros salen a su encuentro y le dicen: «Todos te buscan», invitándole a que prosiga la tarea de sanar interrumpida la tarde anterior. Pero Jesús desatiende el deseo de los capitaneados por Pedro y sigue los dictados marcados por su Padre y que ha escuchado durante la

32 Casi siempre aparece como portavoz del grupo, sobre todo en el Primer Evangelio (Mt 15,5; 16,16.22; 17,4.24; 18,21; 19,27), cuyo autor tiene una especial admiración por su figura, dada su relevancia en la fundación de la Iglesia. 
oración: «Vámonos a otra parte, a las aldeas cercanas, para predicar también alli; que para eso he salido» $(1,36-38)^{33}$.

El caso más sonado tiene lugar, cuando Jesús pregunta a los discípulos, para que le digan quién es él y Pedro responde con decisión una trascendental confesión de fe: «Tu eres el Mesías» $(8,29)$. En la transfiguración también toma la palabra ante los hermanos Santiago y Juan y entre encantado y asustado dice: "Maestro, iqué bueno es que estemos aquí! Vamos a hacer tres tiendas, una para ti, otra para Moisés y otra para Elías» $(9,5)$. En otra ocasión, ya en el camino hacia Jerusalén, le dice a su Señor, recordándole la recompensa que merecen sus seguidores: "Ya ves que nosotros lo hemos dejado todo y te hemos seguido» (10,29). Conocemos bien la respuesta dada por Jesús. Ya en Betania Pedro constata ante los demás la efectividad de un signo realizado por Jesús: «Maestro, mira, la higuera que maldijiste se ha secado» $(11,21)$.

Ese protagonismo se alarga de una manera bien especial durante la última cena pascual, celebrada en Jerusalén. Ante las palabras de Jesús, poco antes de entrar en la pasión, «todos vosotros os escandalizaréis, como está escrito: "Heriré al pastor y se dispersarán las ovejas". Pero cuando resucite, iré delante de vosotros a Galilea», Pedro replica: «Aunque todos caigan, yo no». Y a la respuesta de Jesús: «En verdad te digo que hoy, esta misma noche, antes de que el gallo cante dos veces, tú me habrás negado tres», su insistencia no puede ser más decidida: «Aunque tenga que morir contigo, no te negaré» $(14,24-31)$.

\section{C) LA PERSpectiva testimonial}

Situado Pedro en el discipulado en su momento fundacional, nos interesa relacionarlo ahora, en perspectiva testimonial, con nuestra existencia creyente de hoy. Hemos elegido una óptica bien concreta de gran actualidad: comprobar como la figura de nuestro protagonista, se refleja en los hombres de hoy, dispuestos a seguir a Jesús. En realidad Pedro es el prototipo de discípulo de la primera época y también de todos los tiempos, por lo que nos puede servir de modelo en el presente en la búsqueda de nuestra identidad creyente ${ }^{34}$. Se trata de cuatro momentos sucesivos, de

\footnotetext{
33 Para una detallada interpretación de este texto, cf. Luis Ángel Montes Peral, Jesús orante. La oración trinitaria de Jesús (Salamanca 2006; Publicaciones de la UPSA) 96-98.

34 Tiene toda la razón K. STоcK, Boten aus dem Mit-Ihm-Sein (Roma 1975), cuando presenta a Pedro de forma bien convincente como el tipo de los discípulos de la primera
} 
signo bien distinto cada uno de ellos. Tres son positivos, el cuarto francamente negativo.

\subsection{Vocación $(1,16 s)$}

En el marco de su singular elección y opción por Jesús destacan la vocación y misión, de las que fue objeto por parte de Jesús. Todo ocurrió hacia el año 27 de nuestra era, en algún lugar de Galilea no identificado y cercano al mar. Allí recibe Pedro su llamada, junto con su hermano Andrés y los hijos de Zebedeo, Santiago y Juan (1,16-20) ${ }^{35}$. La vocación de los cuatro primeros testigos del cristianismo ofrece estos rasgos esenciales, con los que los discípulos de todos los tiempos nos identificamos. Pedro pasa por estos estadios consecutivos: es vocacionado; es urgido a seguirlo; es elegido para una misión comunitaria. Y responde con un sí generoso.

* Es vocacionado: Jesús lleva la iniciativa; es él quien llama a Pedro, como a los otros tres y a cada uno de nosotros. Se acerca a su persona, le clava la mirada y le invita con apremio.

* Es urgido a seguirlo, a ir detrás del Maestro de forma personal en comunidad: «Venid en pos de mí». Ese seguimiento conlleva compartir su estilo de vida, asimilar sus actitudes personales, amar como él ama. Lo que implica una existencia relacionada, puesta en acción, mirando una y otra vez el comportamiento del que es digno de ser imitado.

* Es elegido para una misión comunitaria: Jesús le encarga una tarea con otros, expresada en un lenguaje simbólico muy apropiado a la situa-

hora y de todos los tiempos. Su tarea consiste preferentemente en el conocimiento de Cristo. Conocerlo, sí, pero también seguirlo, compartir su vida y representarlo. Precisamente esta es la misión de todos los creyentes en cualquier tiempo de la historia. Qué duda cabe que en la puesta en práctica de su misión, no todo es positivo en Pedro, como tampoco en la de los cristianos de hoy y de siempre. Pueden darse infidelidades de distinto tipo, pequeñas o grandes faltas de fe, insensibilidad para conocer en hondura las enseñanzas del evangelio y el mensaje de la cruz. Hasta pueden darse graves negaciones.

35 Desde otros puntos de vista he abordado este tema de forma minuciosa en L. Á. Montes Peral, «El seguimiento en la historia de Jesús y en la vida de los discípulos», en Tras las huellas de Jesús. Seguimiento y discipulado en Jesús, los Evangelios y el Evangelio de dichos $Q, 9-100$. El conjunto de estos textos, nos proporcionan los elementos más fundantes para ser aquí y ahora cristianos de verdad. Decisivo es que sepamos concretarlos en el quehacer cotidiano, tanto en la vida personal como comunitaria. Concreción que nos urge ponernos bajo el amparo de la Palabra de Dios, interpretarla y seguirla. Como a Pedro puede ser que necesitemos tiempo y esfuerzos, para ir progresando en lo que Jesús dice y hace, a pesar de las pequeñas o grandes incomprensiones y cobardías. 
ción: «Os haré pescadores de hombres». Volveremos de nuevo a la misión con sus concreciones.

* Responde con un sí generoso. Hasta aquí ha sido Jesús quien primero ha obrado. Ahora es Pedro quien actúa: deja la familia, el trabajo y los bienes, las tres cosas más preciadas que tiene, y sigue sin dudarlo al que se ha hecho el encontradizo de forma tan soberana: «Inmediatamente dejaron las redes y lo siguieron».

Desde que Pedro, obediente a la llamada de Jesús, empezó el discipulado, el ser cristiano en todos los lugares y en las distintas épocas de la historia tiene las mismas características. En el bautismo el cristiano recibe la llamada de Jesús a través de sus padres y padrinos, cuando es un niño. Con el paso del tiempo se irá concretando esa llamada de forma personal y consciente, libre y responsable. Entonces se comprometerá a caminar junto a Jesús, a aceptar la misión encomendada y a estar dispuesto a preferir a Jesús por encima de la familia, los bienes y el trabajo. Lo que hicieron Pedro y Andrés, Santiago y Juan integra lo esencial del ser cristiano. De ahí que Marcos considera la vocación de Pedro como ejemplar para cualquier creyente de lea el Evangelio y, convertido, le preste atención y crea en él $(1,15)$. Mirar a Pedro significa tanto como estar dispuesto a ponernos en disposición de aceptar el reto cristiano en contraste con el mundo, que Jesús plantea invariablemente a sus seguidores. La discipulogía de Marcos en la figura de Pedro se ha convertido por derecho propio como el elemento crucial del ser y quehacer de los creyentes de todos los tiempos.

\subsection{La misión (6,7-13)}

En Marcos no hay una misión especial para Pedro como en Mt 16,1719. Está comprendida dentro de la dada por Jesús al grupo de los Doce y aquí no se le menciona individualmente. La misión comprende estos rasgos fundantes, que competen también a los cristianos.

* Salida hacia los otros, dignos de ser amados y servidos. Para ello hay que reconocer sus necesidades y tratar de solucionarlas en la medida que a cada uno le resulta posible.

* Estar fascinados de tal manera por el anuncio y la implantación del reinado de Dios, que las necesidades personales se reducen al mínimo. De ahí la escasez de los medios empleados.

* Entrar en las casas y anunciar la buena noticia de la paz, como componente esencial de la llegada del reino. «Quedarse en la casa hasta ir a otro sitio» $(6,10)$ significa tanto como conocer a las personas en sus situa- 
ciones concretas, donde viven con su familia, donde despliegan sus relaciones, iluminando todo ello con el mensaje evangélico.

Pedro y el resto de los Doce llevaron a cabo esta tarea mediante la predicación de la conversión al reino, el echar demonios, ungir con el aceite a los enfermos y curarlos $(6,12 \mathrm{~s})$. El anuncio del mensaje y la lucha contra el mal en las situaciones concretas llevan consigo la visualización del reino con palabras, con hechos y con signos. Esa es precisamente la misión de la Iglesia en todas las épocas de la historia. Cada uno de los que pertenecen a la comunidad eclesial está llamado a salir al ancho mundo sin temer las dificultades, porque el Señor está con nosotros y quiere que nos convirtamos en sus colaboradores en la trasformación de la sociedad en una familia de hijos y hermanos en alternativa a los valores reinantes.

\subsection{Confesión en Cesarea de Filipos y reprensión de Jesús}

Uno de los mayores teólogos del siglo XX, Paul Tillich ha formulado con acierto el significado excepcional de esta confesión de Pedro así: «El cristianismo no nació con el nacimiento del hombre 'Jesús', sino en el momento en que uno de sus seguidores se sintió impulsado a decirle 'Tú eres el Cristo'. Y el cristianismo seguirá existiendo mientras haya hombres que repitan esta aserción. Porque el acontecimiento en que se basa el cristianismo posee dos vertientes: el hecho que llamamos 'Jesús de Nazaret' y la recepción de este hecho por parte de quienes recibieron a Jesús como el Cristo. Según la tradición primitiva, el primero que recibió a Jesús como el Cristo se llamaba Simón Pedro»36.

Esta confesión petrina se alza entonces como el articulus stantis et cadentis Ecclesiae. Existe comunidad cristiana allí donde se afirma a Jesús de Nazaret como el Mesías de la expectación judía. En cambio la Iglesia se derrumba donde se niega o relega esta confesión. Por algo los

36 P. TIllich, Teología sistemática. Volumen II. La existencia y Cristo (Barcelona 1973) 133. El cristianismo no es una ideología intemporal, basada en mitos eternos. Tampoco un cúmulo de enseñanzas cerradas en sí mismas sin posibilidad de transformación y progreso. El cristianismo es Jesús de Nazaret, proclamado como el Cristo. Lo más crucial en el cristianismo depende de su vida y está marcado esencialmente por su destino. En realidad surge cuando sus seguidores confiesan su persona como el Enviado de Dios y aceptan su obra como portadora de sentido y salvación. Allí donde se alza Jesús con su obra y se confiesa que es el Mesías Salvador, portador de un Nuevo Ser y una Humanidad Renovada, está presente de lleno la cristología. En pocas palabras: el cristianismo es encuentro con la persona de Cristo. 
seguidores de Jesús nos llamamos cristianos, es decir: los confesores de Jesús de Nazaret como el Cristo, el Mesías de Dios. Con este nombre nos han distinguido a lo largo de la historia. La roca que es Pedro encuentra

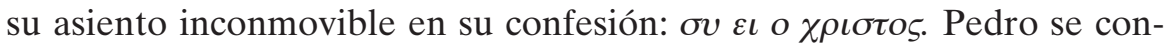
vierte así en la figura clave del cristianismo primitivo, como la roca inconmovible, el fundamento imprescindible de las comunidades de todos los tiempos. Su confesión vale como «das von Petrus dem Felsen Gesagte nur von ihm, dem historischen Apostel, der ein für allemal das irdische Fundament, den das ganze trangende Anfang der künftig zu bauende Ekklesia darstellt» 37 .

Pero conviene entender en su justa medida, lo que significa este mesianismo, que no es político sino religioso, que no es triunfante sino doliente, como se deduce de las palabras que Jesús dice, inmediatamente después de la confesión $(8,31)$. No lleva a la exaltación terrena sino a la humildad de la entrega hasta la humillación final. Algo que en el primer momento no entendieron los discípulos, ni tan siquiera Pedro, que trata de situar a Jesús en las concepciones tradicionales del mesianismo, como una figura política de relumbrón y triunfante $(8,32)$. Sus intereses personales, y quizás familiares, así se lo reclamaban. Pero Jesús rechaza este modo de pensar con inusitada vehemencia. Una pretensión así no puede provenir de Dios, sino de Satán, el tentador $(8,33)$.

La reprensión de Jesús sin duda hizo mella en Pedro, aunque no dejó de hacer de portavoz de los discípulos más cercanos $(9,5)$ y de los discípulos en general $(10,28)$. Tuvo que pasar el acontecimiento del calvario y la experiencia de la resurrección, para que los seguidores de Jesús comprendiéramos que su mesianismo nada tiene que ver con el triunfo fácil sino con el abajamiento difícil. Pasa por la cruz y se realiza en ella. Sólo el Mesías doliente que es Jesús encuentra el beneplácito del Padre, Señor y Padre del reino. Tergiversar su significado significa tanto como no entender el sentido de la vocación y misión tanto de Cristo como de los cristianos. Para el pasado, el presente y el futuro de la fe juega una importancia excepcional la debida intelección del mesianismo que verificó Jesús con su historia y destino y del que nosotros participamos. No cabe duda que exis-

37 (O. Cullmann, Petrus. Jünger. Apostel. Märtyrer, 236). «Lo dicho por Pedro, la roca, sólo por él, el Apóstol histórico, que representa el fundamento terreno de una vez para siempre, el comienzo, que soporta el todo, de la Iglesia a construir en el futuro». La confesión en la mesianidad de Jesús se ha convertido así para los cristianos en la roca inconmovible, en la que se funda y sostiene para siempre la Iglesia. Con todo el significado eclesiológico no aparece, ni siquiera se insinúa, en el EvMc. 
te una coparticipación mesiánica por parte de los fieles seguidores de Cristo, empezando por Pedro ${ }^{38}$.

\subsection{Las tres negaciones (14,66-72)}

La negación de Pedro está enlazada perfectamente con el juicio judío contra Jesús, tal como estaba consignada en la historia de la pasión premarquina. Hay que pensar que no se trata de una escena añadida posteriormente, como algunos piensan ${ }^{39}$. Encaja perfectamente y tiene pleno sentido en el conjunto del relato. La narración se aparta por un momento del destino de Jesús y se centra ahora en el comportamiento de Pedro. El evangelista parte del convencimiento de que lo que los hechos, que va a ofrecer resultan bien relevantes para el discipulado, contemplando de cerca el cobarde comportamiento del primero de los seguidores del Maestro. Previene ante el desgraciado hecho, de que el discipulado puede sucumbir, como queda de manifiesto de manera paradigmática en el caso extremo de Pedro.

\subsubsection{Los antecedentes de las negaciones}

Cuando Jesús anuncia con solemnidad la huída de sus más allegados, llegado el momento de la prueba, Pedro, más seguro que nunca, no atiende a las palabras de su Maestro, desmarcándose de tal cobardía con presuntuosa seguridad (14,26-31). Tal arrogancia le jugará una mala pasada, como nunca lo hubiera pensado. No sólo abandonará a Jesús, acabará negándolo en tres ocasiones sucesivas. Antes, durante la agonía de Jesús en Getsemaní, se quedará dormido por el cansancio y permitirá que su Señor ore solo y siga su propia suerte en el camino de dolor, en el que ya ha entrado $(14,66-72)$. Aparece con un carácter entusiasta, muy seguro de sí mismo, aunque siempre está dispuesto al pronto arrepentimiento, cuando la situación así lo exige.

\subsubsection{Pedro sigue a Jesús desde la distancia}

Las tentaciones tienen su preparación en 14,54, cuando apresado Jesús es enviado al palacio del sumo sacerdote, para ser juzgado. «Pedro lo fue

\footnotetext{
38 Cf. «El mesianismo colectivo de los discípulos» en L. A. Montes Peral, Tras las huellas de Jesús. Seguimiento y discipulado en Jesús, los Evangelios y el Evangelio de dichos $Q, 58$-60. Jesús, el Cristo, no sólo trae consigo el reino, sino que hace partícipe de su pleno poder a otros, que libremente lo han acogido.

39 Así sostienen importantes autores como D. Dormeyer, G. Klein, G. W. H. LAmpe, E. Linnemann, G. SCHNEIDER. Con todo, la mayoría de los comentaristas mantienen la opinión, que yo hago mía aquí. Ambos relatos están perfectamente enlazados en el combinado global.
} 
siguiendo de lejos, hasta el interior del patio del sumo sacerdote; y se sentó con los criados a la lumbre para calentarse». No cabe duda que este versículo tiene una clara intencionalidad, que conviene descubrir. El discípulo entusiasta, que ha estado implicado de lleno en el seguimiento del Maestro, ahora se está desligando de él, dada la peligrosidad que están tomando los acontecimientos. Y así contempla los hechos «desde lejos», no queriendo que nadie reconozca su identidad. Se contenta con mantenerse a salvo en la distancia y enterarse con saber lo que pasa. En realidad está cesando en el discipulado, ya que no sigue a Jesús desde la cercanía; no se implica desde dentro en cuanto sucede. Su fe se reblandece; no lo ha abandonado del todo, pero está cercano a la catástrofe que se aproxima. Ha perdido la seguridad y la fortaleza de la verdadera confianza en el Señor.

\subsubsection{La verdad y originalidad de las negaciones}

Las negaciones de Pedro corresponden sin duda a la verdad de los hechos históricos. El relato marquino ${ }^{40}$ es el que más nos acerca a la verdad de los hechos, que puede ser que tengan como fuente, ya lo hemos insinuado anteriormente, un relato del mismo Pedro. Una de las cosas que más sorprende es que la traición de Pedro tenga como punto de partida el encuentro con una persona tan insignificante como una sencilla criada. Resulta muy difícil pensar que algún grupo de la comunidad primitiva hubiera podido inventar un hecho de estas características, de no haberse producido, por mucha inquina que se tuviera al protagonista ${ }^{41}$.

El relato escalonado está muy bien construido y los personajes perfectamente tratados en su psicología. Alguien ha calificado esta narración con pleno acierto como «una pieza maestra en el retardación y aceleración de la tensión» («ein Meisterstück im Retardieren und Sich-Steigern der Spannung» ${ }^{42}$. Constituye el momento más bajo de su fe, el peor suceso acontecido en su vida de relación con el Maestro, que para más desolación se encuentra detenido, está siendo juzgado por las mayores instancias judías y a punto de ser condenado a muerte.

40 Las particularidades existentes en los distintos evangelistas son diferentes. Pero los cuatro concuerdan en tres hechos esenciales: a) que Pedro negó a Jesús en tres ocasiones; b) que cantó el gallo; c) que todo ocurrió conforme a lo predicho por Jesús (Cf. R. SCHNACKenburg, El Evangelio según San Marcos 2/2 (Barcelona 1976; Herder) 295s.

41 Cf. A. SchweitZer, Das Evangelium nach Markus (NTD 1; Gotinga 1967; Vandenhoeck\&Ruprecht) 189.

42 J. Gnilka, Petrus und Rom. Das Petrusbild in den ersten zwei Jahrhunderten. (Friburgo. Basilea. Viena 2002) 66. Cf. también R. PESCH, Das Markusevangelium II, 448, que es de quien procede la cita. 


\subsubsection{La constatación de la traición}

Teniendo en cuenta estas circunstancias y a pesar de lo que había dicho horas antes de la cena pascual de que él no caería, aunque todos lo hicieran, que no le negaría, aunque tuviera que morir con él, no confiesa a su Señor. Nada menos que le niega por tres veces. Y lo hace en dos ocasiones delante de una sencilla criada, que se mezcla en los hechos sin demasiada convicción; y la tercera vez ante presentes no identificados, que han descubierto su habla galilea y siguen la pista descubierta por la sirvienta. Estamos ante la hora más negra de su vida, que permanecerá siempre en su recuerdo. No para hundirse en él, sino para entregarse con más fidelidad a su Señor. Aquí radica parte de la grandeza de su fe gravemente probada.

Primera negación: Estando en el patio del sumo sacerdote una mujer del servicio del sumo sacerdote pone en aprieto a Pedro, acusándole de forma bien directa de ser discípulo del que está siendo juzgado por su peligroso comportamiento ${ }^{43}$. El que la fámula describa a Pedro como uno que andaba con el Nazareno, puede hacer relación al hecho de que la comunidad de Jerusalén fue denominada como «la secta de los nazarenos» (Hch 24,5). Quien escribió la pasión, pocos años después del juicio contra Jesús, perteneció a ella y Marcos ha mantenido la narración de los hechos, tal como los había recibido.

Volviendo al relato, comprobamos cómo el aprieto, en el que se encuentra metido Pedro, no le permitirá salir indemne en su fe. Con cobardía niega cualquier relación con Jesús: «No sé ni entiendo lo que dices» (v. $68)^{44}$. Pedro ha tomado conciencia de la seriedad de la situación, que puede acabar con la vida del Maestro, y se desliga de él sin contemplaciones, para no correr él el mismo destino. El miedo puede más que la permanencia en la fe. No se afirma que Pedro percibiera el canto del gallo, pero el evangelista tiene especial cuidado en informar del singular hecho, que pudo suceder en la media noche hasta las tres de la mañana ${ }^{45}$. De esta manera certifica la verdad de lo que Jesús había predicho $(14,30)$.

\footnotetext{
43 Los cuatro evangelistas coinciden en expresar que en la primera tentación tentación sólo estaban presentes una sirvienta y Pedro (Mt 26,69; Lc 22,56; Jn 18,17: afirma que la mujer era la portera de la casa del sumo sacerdote).

44 Para comprender el significado preciso de la respuesta de Pedro, recogida en un griego incorrecto, cf. J. GNILKA, El Evangelio según San Marcos II (BEB 56; Salamanca 1986; Sígueme) 342. Una cosa queda bien clara: Pedro se distancia de su Maestro, no desea saber nada de su persona. Una forma bastante clara de negación, al no querer abiertamente implicarse en el asunto, del que se está tratando.

45 Cf. R. Pesch, Das Markusevangelium II, 449.
} 
Segunda negación: Pedro sale fuera del zaguán y no tiene la intención de volverse atrás en su negación, sino que persevera en su incredulidad, aunque sin duda el primer canto del gallo tuvo que revolverle el interior en extremo. Una de las cualidades de las mujeres, que pueden convertirse en vicio, es la tenacidad en los propios propósitos. Al volverse a encontrar fuera con Pedro (quizá lo ha perseguido), la mujer persiste en su acusación. Pedro, fuera de sí, vuelve a negar su relación con el Maestro con mayor decisión. La fe está a punto de quebrarse por completo.

Tercera negación ${ }^{46}$ : Proviene de los presentes, que se han reunido fuera, deseosos de saber en qué va a acabar el proceso contra el Nazareno. Implicándose en el incidente, afirman sin dar lugar a la duda que es uno de ellos, ya que es galileo ${ }^{47}$. Ante comentario tan peligroso Pedro opone una resistencia mayor, que puede hacer más creíble sus palabras. Entre maldiciones lo niega con juramento: «No conozco a ese hombre del que habláis». Ante momento tan peligroso para su integridad física Pedro se siente invadido por el pánico y se desliga por completo de Jesús. Por unos instantes ha perdido por completo la fe.

El seguimiento de Jesús termina dramáticamente para Pedro con la tercera negación. Resulta difícil mantenerse firme en el discipulado, cuando las circunstancias se vuelven tan adversas. Pero la caída de Pedro no entorpece la firme decisión de Jesús de congregar de nuevo a los discípulos a raíz de la resurrección $(14,27 \mathrm{~s})$. El lloro de Pedro supone la vuelta a la regeneración, la nueva entrada en la fraternidad del Maestro. Al cantar por segunda vez el gallo, Pedro que se ha quedado solo con su angustia y se percata de la gravedad de la traición cometida, llora ${ }^{48}$. En realidad el lloro está indicando que Pedro, después de la caída, está decidido a seguir siendo discípulo de Jesús. Su sincero arrepentimiento prepara el hecho fehaciente de que el Resucitado se la apareció, como indica el penúltimo versículo del texto marquino.

46 Según Lc 22,59 entre la segunda y tercera negación transcurrió una hora. Esta tercera tentación es narrada de forma diversa por los distintos evangelistas.

47 Según Mt 26,73 los que estaban allí le espetan a Pedro que se le nota en su acento, que es uno de Jesús.

48 Mateo y Lucas elevan el tono, afirmando que «lloró amargamente» (Mt 26,75; Lc

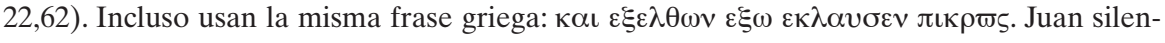
cia el lloro, ni siquiera lo sugiere. 


\subsection{5. ¿Qué sintió Pedro en su «amargo lloro»?}

Los sentimientos íntimos de Pedro en esa hora baja de su vida sin duda pertenecen a su intimidad personal, en la que no debemos meternos. Pero dado que su puesto en la Iglesia tiene especial relevancia, podemos adentrarnos, en lo que los evangelistas quisieron expresar, cuando constataron el lloro de Pedro. En primer lugar una vergüenza muy grande ${ }^{49}$. Pedro miró dentro de su interior desolado y se percató de su vaciedad. Estaba con las manos vacías, peor aún manchadas, ante su Señor, ya que había renegado de él de la manera más mezquina y vergonzante. ¿Se puede hacer algo más atroz que el desmantelamiento de la amistad mediante un acto de incalificable cobardía? El maestro del alma ha dejado de ser tal, ya que ha sido destruido el mutuo consuelo de la fe (Rom 1,12).

Junto con la vergüenza por su cobardía sintió sin duda también arrepentimiento. «El arrepentimiento de Pedro señala la salida. Sin embargo, durante la pasión no se verán los frutos de ese arrepentimiento. Pedro no estará al pie de la cruz. El arrepentimiento da a entender que la gracia ha salvado al discípulo. La comunidad tiene que sentirse reconfortada con esa experiencia» ${ }^{50}$. Su fe caída vuelve a resurgir con el recuerdo emocionado de su Señor. Las lágrimas constituyen la certificación de la propia culpa y del dolor intenso por la triple negación ${ }^{51}$.

Pedro llora su propia miseria e impotencia. El que hace un par de horas había asegurado ante Jesús y los demás discípulos su fidelidad hasta la muerte $(14,31)$, tiene que reconocer su debilidad y admitir su fracaso. Se ha comportado como un perfecto cobarde y, lo que aún es peor, como un desleal. Mientras Jesús ha reconocido públicamente ante el sumo sacerdote su identidad más profunda (14,61s), Pedro rechaza cualquier relación con el Maestro, al que en memorable ocasión le había confesado como Mesías $(8,29)$. En lugar de negarse a sí mismo, para seguir a su Señor $(9,34)$, niega a su Señor, para escapar de una situación difícil. Jesús debe soportar una afrenta más en el doloroso camino hacia la muerte. Es el destino trágico del Hijo del Hombre $(8,31 ; 9,31 ; 10,33)$.

\footnotetext{
49 El Papa Francisco ha afirmado al principio de un discurso esa vergüenza sentida por su antecesor en el primado de la Iglesia: «Pedro había pasado por muchos estados de ánimo, en aquel momento: la vergüenza, porque se acordaba de las tres veces que había negado a Jesús» (Discurso del Papa Francisco a la LXVI Asamblea Plenaria de la Conferencia Episcopal Italiana del 19.05.2014: Ecclesia 3.737 [2014] 29).

50 J. GNILKA, El Evangelio según San Marcos II, 344.

51 W. Schmithals, Das Evangelium nach Markus II (ÖTKNT 2/2; Gütersloh - Würzburg 1979) 655 .
} 
Pedro llora también por su falta de coherencia en los hechos y en la palabra dada. Ese precisamente, ese es el material humano, con el que Jesús opera y al que encomienda una misión fundamental en la constitución y buena marcha de la comunidad. Pero la negación no es la última palabra de Pedro, que sabe que las puertas de la salvación están abiertas siempre para los arrepentidos. Al romper a llorar, está mostrando su sincero dolor de corazón y, lo que resulta más importante, se atiene a la misericordia divina ${ }^{52}$. Sus lágrimas constituyen la prueba más fehaciente de su decisión de cambiar de vida, apoyado ahora no en sus propias fuerzas, sino que en el perdón que le brindará el Resucitado (16,7).

Contempladas ya así las cosas, la intención de la narración consiste en informar de un hecho fehaciente, ocurrido en un momento especialmente difícil. En modo alguno tiene una intención moralizante, tampoco pretende desprestigiar a Pedro y echarle en cara su grave pecado, menos aún encontramos en él motivaciones cristológicas de ningún tipo. Más bien recoge algo histórico que sucedió en la pasión de Jesús, del que los lectores pueden sacar las consideraciones que les parezcan oportunas y aprender en cabeza ajena.

La triple negación de Pedro descubre con meridiana claridad lo solo que se encuentra Jesús, llegada la hora de las tinieblas. ¡Ya no puede confiar ni tan siquiera en el discípulo que parecía más firme y fiel en su andadura terrena! No sólo le ha abandonado, también ha renegado de él de forma persistente y ruin. Mientras Pedro recupera su fe mediante el arrepentimiento y el sollozo, Jesús sigue su camino de soledad, prosigue su pasión en ascendente sufrimiento, sin olvidarse por un momento de su entrega a los hombres.

\subsubsection{Lo que podemos aprender de las negaciones de Pedro:}

Algo queda meridianamente claro en lo ocurrido con Pedro: En el camino de la fe, cuando confiamos en nuestras propias fuerzas y nos olvidamos de poner toda nuestra confianza en Dios, tarde o temprano seremos víctimas de nuestras debilidades y caeremos en el pecado, más o menos grande, por no habernos apoyado totalmente en el Señor. Poco antes de su pasión, Jesús mismo recordó a Simón y en él nos lo recuerda a nosotros: «Velad y orad, para no caer en tentación; el espíritu está pronto, pero la carne es débil » $(14,38)$. Eso fue precisamente lo que no hizo Pedro.

52 Cf. J. MARCus, El Evangelio según Marcos (Mc 8-16) II (BEB 131; Salamanca 2011; Herder) 1181. 
Se apoyó exageradamente en sus propias fuerzas, que le llevaron al desastre ${ }^{53}$. «Un pequeño tropiezo basta para dar al traste con el orgullo humano; es necesario seguir a Jesús humildemente por su camino y pedir fuerza para no sucumbir a la tentación» 54 .

Pedro había sido advertido de manera muy seriamente por Jesús $(14,30)$, pero no le hizo caso. Creyó más en sí mismo que en las palabras de su Maestro y Señor. No se dejó enseñar por él y como consecuencia vino la caída. En otra ocasión sonada, cuando quiso evitarle el camino de la cruz, Jesús ya le hizo una advertencia muy seria con un fuerte reproche:

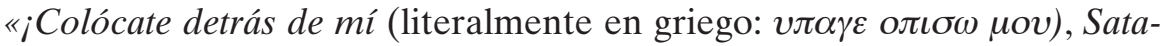
nás! ¡Tú piensas como los hombres, no como los Dios» (Mc 8,33). Llega a llamarle Satanás, porque en lugar de tener los pensamientos de su Padre, concuerda en el modo de pensar con Belzebú, el principio de los demonios $(3,22 \mathrm{~s})$.

Pero Pedro continuó en sus treces y en lugar de prestar atención a sus advertencias, siguió su propio camino, que acabó de forma bien lamentable. Por eso la actitud del verdadero discípulo consiste en ponerse detrás del Maestro, escuchar la seriedad de sus palabras y ponerlas en práctica. El discípulo no puede caminar delante, marcándole el camino al Maestro y diciéndole lo que debe hacer. Bien al contrario su cometido está en ir detrás, seguirlo con humildad imitando sus virtudes, prestando atención a sus enseñanzas, aprendiendo de su persona y atreviéndose a llevar la cruz, como él hizo.

\subsection{7. ¿Naufragó Pedro en su fe?}

Seguro que no. Aunque Mc no aborda el tema de manera directa, lo da a suponer claramente en el modo cómo concluye su relato. Después de las negaciones hace dos alusiones a la figura de Pedro. Una inmediatamente: «y rompió a llorar» (14,72c). Otra en el penúltimo versículo del escrito: «Pero id a decir a sus discípulos y a Pedro» (16,7a). Al cantar el gallo la segunda vez, Pedro llora de vergüenza y de arrepentimiento. Se encuentra en el camino de la sincera conversión, después del pecado cometido. La buena noticia que reciben las mujeres hace una alusión

\footnotetext{
53 Pero Simón Pedro, según nos relata más tarde el Cuarto Evangelio, supo aprender de sus flaquezas. Cuando Jesús por tres veces le pregunta, si le ama, le contesta con humildad: «Tú sabes que te quiero» (Jn 21,15.16.17). Ya no se apoya en su propio yo; no dice: Yo te quiero. Ahora se siente sostenido por el yo del Resucitado y responde precavido: Tú sabes que te quiero.

54 R. Schnackenburg, El Evangelio según San Marcos 2/2, 297.
} 
expresa a Pedro. El Resucitado pasa por alto la flaqueza de Pedro y el abandono de los demás y mantiene su palabra de ir «delante de vosotros a Galilea» (14,28). Al irrumpir la luz, se impone un perdón sin reproches, que constituye la suma del verdadero perdón.

Pedro se sintió perdonado por Jesús, después de su amargo arrepentimiento. Lo que le instaló en una vida nueva en continuidad, pero también en complementación a la anterior. Ahora experimenta en sus propias carnes algo decisivo para su vida: No podía apoyarse en sus propias fuerzas, a la hora de seguir a su Señor. Necesitaba apoyarse en su fuerza y sentir la gracia de su incondicional perdón.

\subsubsection{La aparición del Resucitado a Pedro}

El joven, que anuncia a María de Magdala, a María la de Santiago y a Salomé la buena noticia de que el crucificado ha resucitado $(16,6 \mathrm{a})$, «señala a Pedro como destinatario del mensaje pascual de que Jesús ha resucitado y de que irá delante de los discípulos a Galilea» $(16,6 b)^{55}$. Marcos hace aquí mención explícita a una aparición del Resucitado a Pedro, pero no la relata ${ }^{56}$. Esa breve referencia tiene una gran significatividad. Conviene no pasar demasiado aprisa esta afirmación, ya que contiene apreciaciones implícitas de especial relevancia:

Pedro ha sido perdonado; incluso ha sido confirmado en su puesto de presidencia entre los primeros discípulos. Deja bien claro, que el Resucitado atendió a las lágrimas del arrepentido con toda sinceridad y le instaló de nuevo en el puesto que había ocupado durante su andadura terrena. Pedro experimenta un nuevo comienzo, del que no se habla al final del Evangelio, pero que Marcos sin duda conoció por la historia del cristianismo primitivo. Aquí empieza su fe en Cristo Resucitado, una fe que ya no es objeto de estudio por parte de Marcos. La constata, pero no la describe, ni desarrolla, porque excede lo pretendido en su obra ${ }^{57}$.

Sin duda Pedro aprendió mucho de sus negaciones. Comprendió que la fidelidad corresponde a Dios y a su Señor Jesucristo. Propio de los hombres son las traiciones, como las de Judas Iscariote, los abandonos como lo de los discípulos y las humillantes negaciones, como las suyas. El Resu-

\footnotetext{
55 M. Bockmuehl, Simón Pedro, 47s.

56 Quien sí la relata, en una pasaje de gran importancia es Mateo (cf. L. Á. MonTES Peral, «La misión universal (Mt 28,16-20)» en Tras las huellas de Jesús 441-465.

57 Marcos supone, aunque no lo afirma de una manera explícita, que Pedro fue el primer testigo de la resurrección de Jesús (en contra de lo que sostiene 16,9, que no es obra del evangelista). En este sentido está de acuerdo con 1 Cor 15,5 y Lc 24,34.
} 
citado, que guarda identidad con el Crucificado, posibilita salir de las mezquindades humanas y está dispuesto a un nuevo comienzo, en el que la acogida y el perdón constituyen elementos esenciales. Apoyada su fe en la grandeza del amor divino, puede superar el negro trance de su caída en una traición sin nombre 58 .

\section{El retrato de Marcos sobre Pedro}

En el espejo de los cuatro evangelios, debemos al primero escrito la mayoría de las informaciones históricas referentes a Pedro, expresadas con realismo y hasta crudeza. Sin su valiosa contribución hubiéramos perdido datos preciosos para conocer cuál fue su privilegiada relación con Jesús y con los primeros discípulos. Marcos nos ha proporcionado el retrato primero y el más fiable del Pedro histórico, ofreciéndolo a la posteridad creyente. Pero hay que reconocer que con las noticias suministradas - lo mismo que con las proporcionadas por los otros evangelistas y autores del Segundo Testamento- no resulta posible escribir una biografía de Pedro. Nada sabemos de su niñez y juventud. Son bien escasas las noticias sobre su familia y de las condiciones en que vivió antes de encontrarse con Jesús. Lo que conocemos de la etapa del seguimiento del Maestro no podemos ordenarlo en una cronología precisa. En no pocas ocasiones tenemos que recurrir a suposiciones más o menos fundadas.

Pero sí nos proporciona datos que nos permiten trazar un perfil de su persona y conocer circunstancias concretas de determinaron su vida posterior. Efectivamente, «podemos aceptar aspectos centrales, que ponen ante nuestros ojos a Pedro en el horizonte del mensaje de Jesús como discípulo: como uno, al que el encuentro con su Maestro le abrió los ojos para Dios y para su viniente reinado, que desde entonces determinó su vida y le convirtió en testigo del Resucitado más allá de los altos y bajos sufridos» ${ }^{59}$. Marcos nos muestra a un cristiano de la primera hora, del que podemos aprender tanto en lo positivo como en lo negativo de su comportamiento.

Por eso, debemos al primer evangelio escrito los datos fundamentales para trazar los perfiles reales de la figura de Pedro. Marcos no sólo es

\footnotetext{
58 Ha afirmado el Papa Francisco en la fiesta de san Pedro y san Pablo de 2014: «Pedro ha experimentado que la fidelidad de Dios es más grande que nuestras infidelidades y más fuerte que nuestras negaciones».

59 Claus-Peter März, Petrus. Sein Leben, sein Wirken, seine Zeit, 10s.
} 
el que nos ha proporcionado más datos de su historia, sino el primero que ha propuesto una significación teológica de su comportamiento. La comunidad marquina, con su pastor Marcos a la cabeza, concedió una importancia grande a la figura de Pedro ${ }^{60}$. Siempre aparece de modo muy destacado: primero en las listas de discípulos, que se ofrecen a lo largo de la obra, de modo muy especial en la primera parte $(1,16-20.29 ; 3,15-19 ; 5,37$; $9,2 ; 13,3 ; 14,33)$ y después como portavoz indiscutible del grupo de los doce y de los más allegados, sobre todo en la segunda parte $(1,36 \mathrm{~s} ; 8,29$; $9,5 ; 10,28 ; 11,21 ; 14,29)$. A pesar de sus negaciones, el momento más bajo de su vida, Marcos da a entender, al final de su escrito $(16,7)$, que fue el primer testigo de la resurrección. Contemplada la instancia histórica proporcionada por Marcos, Pedro adquiere una importancia básica para la comunidad de los creyentes de todas las épocas de la historia.

El retrato que el evangelista ofrece de Pedro tiene una especial significación, ya que destaca como nadie su figura entre los testigos centrales del Evangelio con sus luces y sombras. Lo presenta con rasgos muy positivos, como pescador, discípulo, apóstol y confesor de Jesús en horas decisivas. Pero no olvida resaltar también aspectos negativos de bulto, como su falta de intelección y de fe, como los demás discípulos, a la hora de comprender aspectos esenciales de la buena noticia del reino $(4,13$; $4,40)$, su tergiversación del verdadero mesianismo de Cristo $(8,32 \mathrm{~s})$ y sobre todo sus negaciones en el momento comprometido de la pasión. Marcos no oculta las debilidades de Pedro del tipo que sean. Bien al contrario, las resalta con el propósito de que nos sirvan de ejemplo, ya que debilidades semejantes se encontraban también entre los creyentes de la comunidad marquina primero, y de los lectores del Evangelio después.

El Pedro marquino fluctúa entre fe e incredulidad ${ }^{61}$, entre la acogida incondicional de su Maestro y la falta de intelección de su mensaje y misión, algo que le hace muy cercano a los cristianos de todos los tiempos. No es un superdotado y mucho menos un superhombre; se trata más bien de una persona de carne y hueso, que sigue la llamada de Jesús, pero que necesita del apoyo firme de su Señor y de la buena voluntad del resto de los discípulos, para poder seguir adelante y cumplir la alta tarea encomendada. Apoyarse en sí mismo le jugó las peores pasadas.

\footnotetext{
60 Después los otros evangelistas siguieron a Marcos, resaltando a Pedro por encima de los otros discípulos.

61 (cf. H. PATtARUmadathil, «Entre la debilidad y la fuerza de la fe»: Selecciones de Teología 210 (2014) 150-160).
} 
Algo que queda de manifiesto en la consideración de su fe. Mediante ella Pedro está íntimamente unido al Evangelio de Jesucristo, Hijo de Dios $(1,1)$ e implicado desde los inicios con sus valores universales $(1,14-$ 17). Acompaña a Jesús durante su actividad por Galilea $(1,29)$, siendo testigo de sus hechos y dichos. Comparte su misión, junto con el grupo de los doce (3,13-16; 6,7-12). Su confesión de Jesús como el Mesías (8,27-29) representa el punto álgido del Evangelio, que tiene como cuestión central y crucial responder a la pregunta quién es Jesús y cuál es su puesto en la historia de la salvación. Pero su incredulidad también resulta proverbial, sobre todo cuando más se necesitaba su apoyo a la causa del Evangelio: Recibe la mayor reprimenda de Jesús que se conoce, por no entender el sentido de su mesianidad $(8,33)$ y en los momentos más comprometidos de la vida de su Maestro lo niega en tres ocasiones (14,66-72), a pesar de que ya había sido advertido de su posible traición (14,26-31).

No cabe duda que en su presentación de la figura de Pedro este retrato real y espiritual dio la pauta al resto de los evangelistas. Éstos añadieron después nuevas noticias, sobre todo eclesiales, para remarcar la importancia capital del primero de los discípulos en la historia de Jesús. Mateo completa a Marcos mediante la presentación de nuevas tradiciones petrinas. La más relevante de todas, la relacionada con la fundación de la Iglesia en 16,17-19. Lucas nos ofrece preciosos pormenores de los primeros tiempos de la comunidad de Jerusalén de la mano de Pedro en la primera parte de los Hechos de los Apóstoles. En la historia de la Pasión, Juan pone a Pedro en paralelismo con el Discípulo Amado. El primado de Pedro, que continúa en los obispos de Roma, tiene su punto de partida en el obra marquina, aunque sólo se explicita en los otros evangelios: Mt 16,17-19; Lc 22,31s; Jn 21, 15-20. Podemos concluir que, los otros evangelistas hacen explícito lo implícito de Marcos.

\section{PEDRo hoy}

Encontrarse con Pedro, sobre todo en la historia de la pasión de Marcos, significa tanto como encontrarse con el conflicto de la fe y el correspondiente compromiso creyente aquí y ahora. Pedro en realidad representa el caso más extremo del comportamiento de los discípulos en la pasión de Jesús. No sólo abandona a Jesús, también le niega y, aunque arrepentido de su traición, no aparece ya ante el Crucificado en el momento de morir, en contraste con las mujeres discípulas. Su fe en esos momentos deja mucho que desear y previene a la comunidad cristiana de 
no apoyarse en uno mismo en el seguimiento, sobre todo en los momentos más difíciles.

En el camino de la fe lo peor que nos puede pasar es confiar unilateralmente en nuestras propias fuerzas. No apoyarnos en la fortaleza divina y en las enseñanzas del Señor. Eso fue precisamente lo que hizo Pedro: se confió en sí mismo y así le fue como le fue: naufragó de la forma más estrepitosa. El hecho de que negara a su Maestro, con el que tan unido estaba, pone de manifiesto que, en el momento decisivo, cuando la propia vida peligra, un amigo puede faltar a la fidelidad, tantas veces profesada, e incluso convertirse en el prototipo del traidor (tanto o más que Judas). Pero supo arrepentirse a tiempo, acogerse a la misericordia divina y al perdón de su Señor. Mediante el propio arrepentimiento y sobre todo apoyado en la gracia divina, recuperó su condición de discípulos y apóstol y continuó con su posición privilegiada en la comunidad primitiva. Se convirtió en el primer representante de la causa de Jesús para los tiempos de su ausencia de la vida terrena.

Llegado el momento, nos revela la tradición, supo asumir el cáliz del martirio, que el Maestro había pronosticado a Santiago y Juan y previsto de manera misteriosa para el resto del grupo de los doce, durante un momento bien solemne, que coincide con su bajada hacia Jerusalén $(10,39 \mathrm{~s})$. Superó con notable éxito sus propias debilidades y asumió la iniciativa, por encargo del Resucitado, de en la congregación postpascual de los discípulos. Se convirtió así en la roca firme, en que se asienta la Iglesia, sostenida por la presencia y actuación de la Trinidad y por la gracia sanante de nuestro Señor Jesucristo. Pero de todo esto nada nos dice explícitamente Marcos, aunque si lanza una sugerencia que lo supone $(16,7)$.

La imagen que tiene Marcos de Pedro es corroborada y hasta fortalecida por los otros evangelistas. En ella podemos reflejarnos los creyentes. Dadas las circunstancias, pasa del mayor entusiasmo por Jesús $(9,5)$ al abatimiento más profundo (14,72). Puede comportarse ante su Maestro de manera dulce $(11,21)$, pero también airada $(8,32)$. Se muestra generoso en sus decisiones $(1,18 ; 6,12.30)$, pero también presto a sacar partido de su generosidad $(10,28)$. Testarudo $(14,27)$ e insensible $(14,37)$, está dispuesto a ceder, cuando la situación así lo exige $(8,33)$. No cabe duda que se comporta como hombre de contrastes, de forma parecida al hombre de hoy. La condición humana se refleja en Pedro de forma magnífica, lo mismo que de primer creyente.

Hay algo que permanece intacto en la historia del cristianismo desde sus inicios. En la existencia creyente resulta imprescindible escuchar y 
acoger la llamada que Jesús, que pasa a nuestro lado y estar decididos a seguirlo a pesar de las posibles debilidades y hasta traiciones, que pueden jalonar nuestra existencia diaria. El éxito del seguimiento, centro de la auténtica espiritualidad, depende de conjugar la acción de Jesús y nuestra propia aportación; pero sabiendo siempre que el Señor nos lleva la iniciativa. Importa no ceder y menos desfallecer en el empresa emprendida, acompañados como estamos en la gracia del Padre, del Hijo y del Espíritu Santo. 